NASA/TM-2003-212214

\title{
Carbon Nanostructure Examined by Lattice Fringe Analysis of High Resolution Transmission Electron Microscopy Images
}

Randy L. Vander Wal and Aaron J. Tomasek

National Center for Microgravity Research, Cleveland, Ohio

Kenneth Street, William K. Thompson, and David R. Hull

Glenn Research Center, Cleveland, Ohio 
Since its founding, NASA has been dedicated to the advancement of aeronautics and space science. The NASA Scientific and Technical Information (STI) Program Office plays a key part in helping NASA maintain this important role.

The NASA STI Program Office is operated by Langley Research Center, the Lead Center for NASA's scientific and technical information. The NASA STI Program Office provides access to the NASA STI Database, the largest collection of aeronautical and space science STI in the world. The Program Office is also NASA's institutional mechanism for disseminating the results of its research and development activities. These results are published by NASA in the NASA STI Report Series, which includes the following report types:

- $\quad$ TECHNICAL PUBLICATION. Reports of completed research or a major significant phase of research that present the results of NASA programs and include extensive data or theoretical analysis. Includes compilations of significant scientific and technical data and information deemed to be of continuing reference value. NASA's counterpart of peerreviewed formal professional papers but has less stringent limitations on manuscript length and extent of graphic presentations.

- TECHNICAL MEMORANDUM. Scientific and technical findings that are preliminary or of specialized interest, e.g., quick release reports, working papers, and bibliographies that contain minimal annotation. Does not contain extensive analysis.

- CONTRACTOR REPORT. Scientific and technical findings by NASA-sponsored contractors and grantees.
- CONFERENCE PUBLICATION. Collected papers from scientific and technical conferences, symposia, seminars, or other meetings sponsored or cosponsored by NASA.

- SPECIAL PUBLICATION. Scientific, technical, or historical information from NASA programs, projects, and missions, often concerned with subjects having substantial public interest.

- TECHNICAL TRANSLATION. Englishlanguage translations of foreign scientific and technical material pertinent to NASA's mission.

Specialized services that complement the STI Program Office's diverse offerings include creating custom thesauri, building customized databases, organizing and publishing research results ... even providing videos.

For more information about the NASA STI Program Office, see the following:

- Access the NASA STI Program Home Page at http://www.sti.nasa.gov

- E-mail your question via the Internet to help@sti.nasa.gov

- Fax your question to the NASA Access Help Desk at 301-621-0134

- Telephone the NASA Access Help Desk at 301-621-0390

- Write to:

NASA Access Help Desk

NASA Center for AeroSpace Information 7121 Standard Drive

Hanover, MD 21076 
NASA/TM-2003-212214

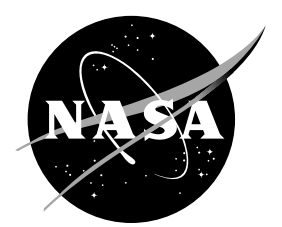

\section{Carbon Nanostructure Examined by Lattice Fringe Analysis of High Resolution Transmission Electron Microscopy Images}

Randy L. Vander Wal and Aaron J. Tomasek

National Center for Microgravity Research, Cleveland, Ohio

Kenneth Street, William K. Thompson, and David R. Hull

Glenn Research Center, Cleveland, Ohio

National Aeronautics and

Space Administration

Glenn Research Center 


\section{Acknowledgments}

This work was supported by a NASA NRA 99-HEDs-01 combustion award (RVW) administered through NASA cooperative agreement NCC3-975 with The National Center for Microgravity Research on Fluids and Combustion (NCMR) at NASA Glenn Research Center (GRC). This work was also sponsored, in part, by the Revolutionary Aeropropulsion Concepts subproject of the Propulsion and Power Project at NASA GRC administered through NASA cooperative agreement NCC3-544 with NCMR at NASA GRC. The authors gratefully acknowledge Gordon M. Berger for assistance with the experiments and Dr. Y.L. Chang for the TEM imaging.

Trade names or manufacturers' names are used in this report for identification only. This usage does not constitute an official endorsement, either expressed or implied, by the National Aeronautics and Space Administration.

Available from

NASA Center for Aerospace Information 7121 Standard Drive

Hanover, MD 21076
National Technical Information Service 5285 Port Royal Road Springfield, VA 22100 


\title{
Carbon Nanostructure Examined by Lattice Fringe Analysis of High Resolution Transmission Electron Microscopy Images
}

\author{
Randy L. Vander Wal and Aaron J. Tomasek \\ National Center for Microgravity Research \\ Cleveland, Ohio 44135 \\ Kenneth Street, William K. Thompson, and David R. Hull \\ National Aeronautics and Space Administration \\ Glenn Research Center \\ Cleveland, Ohio 44135
}

\begin{abstract}
Summary
The dimensions of graphitic layer planes directly affect the reactivity of soot towards oxidation and growth. Quantification of graphitic structure could be used to develop and test correlations between the soot nanostructure and its reactivity. Based upon transmission electron microscopy images, this paper provides a demonstration of the robustness of a fringe image analysis code for determining the level of graphitic structure within nanoscale carbon, i.e., soot. Results, in the form of histograms of graphitic layer plane lengths, are compared to their determination through Raman analysis.
\end{abstract}

\section{Introduction}

Although soot represents one of the very first nanostructured materials, it has rarely been considered as such. For decades, combustion research has focused on its formation and growth. Early studies were heuristic, representing the diagnostic and computational tools available [1]. Later studies have provided detailed insights into its inception and growth from molecular species [2].

As found through both experimental and theoretical studies [3], in fuel-rich environments at elevated temperatures hydrocarbons undergo pyrolysis to produce mainly acetylene. As well described by the hydrogen abstraction, acetylene addition model, (the HACA mechanism) polycyclic aromatic hydrocarbons (PAHs) are formed by incremental $\mathrm{C}_{2}$ addition to benzene [4]. Physical and reactive coagulation among these large PAHs results in soot precursor particles [5, 6]. More recent work has also shown the importance of dimerization among resonance stabilized radicals in producing high molecular mass PAHs [7]. Further mass addition by $\mathrm{C}_{2} \mathrm{H}_{2}$ and PAHs, along with carbonization results in soot [8-10]. Given the complexity and number of reaction steps in soot inception and growth; the effect upon soot internal structure has routinely been ignored.

When occasionally examined, soot internal structure has not been observed to differ substantially among laboratory-scale systems. This likely reflects the similarity of temperature and residence times in buoyancy-dominated flames $[11,12]$ and use of common hydrocarbon gases as fuels [13]. However, careful review of the general carbon literature does reveal that the structure of carbon materials is highly variable and is well known to depend upon the starting material and processing conditions. Carbons derived from different pitches have long been known to be either graphitizable or nongraphitizable [14]. Carbons produced from tars will have different degrees of cross-linking, reflecting the structure of the starting material [15]. Chars derived from biomass fuels have a high degree of cross-linking that prevents 
their graphitization upon exposure to high temperatures [16]. Different coals are known to possess varying degrees of graphitizability [17-19]. Similarly, the nanostructure of carbon black also depends upon the reaction process [20].

The significance of the internal structure of carbon with respect to combustion is its effect upon reactivity. In general, more graphitic carbons are less reactive towards oxidation [21-27]. As a fundamental tenet in carbon science, a more graphitic carbon is characterized by layer planes with larger in-plane dimensions [17]. By virtue of geometry, larger layer planes contain fewer carbon atoms at edge sites relative to basal plane sites. The connection between layer plane dimensions and reactivity towards oxidation is due to the anisotropic reactivity of the graphitic segments comprising the carbon. Carbon atoms within basal plane sites, surrounded by other carbon atoms, exhibit a far lower reactivity towards oxidation than those located at the periphery of such segments (so-called edge sites) [21-27].

For these reasons, processes that induce growth of layer planes will necessarily affect the carbon's reactivity. For example, numerous examples of coal oxidation have found a decline of reactivity with increasing heat treatment [28-32]. Changes in the carbon nanostructure, such as an increase in graphitic layer plane length, have been correlated with this reactivity loss [30-33]. This extension arises from a reorientation/reorganization of material. Layer plane segments can grow by bonding to adjacent graphene segments and by addition of amorphous carbon material within the soot particle [34-37]. Whether thermally or oxidatively induced, an increase in the dimensions of graphene segments corresponds to graphitization and a parallel decrease in reactivity.

High resolution transmission electron microscopy (HRTEM) can reveal the graphitic structure of carbon, i.e., its nanostructure. Such images provide a direct measure of the length, shape and orientation of the graphitic fringes at any particular depth in the materials as determined by the focal plane [38]. As a measure of molecular order, quantification of the graphene segment dimensions could potentially be used to assess the reactivity of carbon towards oxidation. Correlations could then be developed between the extent of graphitic structure and oxidative reactivity, provided an algorithm to extract their size distribution from HRTEM images were available. Towards this goal this work sought to develop such an algorithm for soot.

Lattice fringe analysis has been employed to explain reactivity issues of other types of carbons. Shim et al. sought statistics on fringe length, tortuosity and other orientational order among graphene layers in solid fuel chars [39]. These authors sought to characterize the nanostructure as a function of residence time. This work was motivated by and built upon the observed decline in solid fuel char reactivity with increasing crystallinity. In related work, using HRTEM to examine the fine structure of chars, Zhang et al., identified a critical porosity as the factor determining fragmentation [40]. Moreover, the image analysis revealed an increase in order thereby accounting for the densification of the chars.

Prior to developing such correlations between structure and reactivity it is desirable to first test the robustness of the program for differentiating the varying levels of graphitic structure. To produce a reference set of soots with varying degrees of graphitic order, we applied thermal annealing to an amorphous grade of carbon black. As is well-known in carbon science, the final level of graphitic structure and organization will be dependent upon the combination of temperature and time at elevated temperature [41-42]. For convenience with the instrumental apparatus available, we chose to vary the treatment temperature for a fixed time interval, as described next. The robustness of the algorithm for differentiating the degree of graphitic structure of these soots was then compared to Raman spectra as a traditional benchmark of graphitic materials. 


\section{Experimental}

Samples of carbon black (Cabot R250 from Cabot Corporation) were heat-treated in a LECO EF-400 resistance heated furnace using a graphite crucible under a He atmosphere. The furnace was operated in power mode to maintain temperature stability and reproducibility. The temperature was inferred from factory provided calibration data. The heat treatment was a near trapezoid function of time with the temperature ramp up and cool down lasting less than $30 \mathrm{sec}$ with a soak time at elevated temperature of $10 \mathrm{~min}$. An additional sample was obtained by inductive heating at $3000^{\circ} \mathrm{C}$ for $1 \mathrm{hr}$ duration.

Transmission electron microscope (TEM) images were taken using a Phillips CM200 with Gatan image filter (GIF) for digital imaging with live Fourier transforms having nominal resolution of $0.14 \mathrm{~nm}$. The instrument operated at $200 \mathrm{keV}$ using $\mathrm{a} \mathrm{LaB}_{6}$ filament. Gatan image software, version 3.4 was used for microscope operation. The real-space lattice fringe analysis program, as described later was based on Optimas version 6.5 with a custom windows-based macro interface, using the Gatan images as input.

A Renishaw Model 2000 Raman Microscope that uses a $25 \mathrm{~mW}$ Ar Ion laser operating at $514.5 \mathrm{~nm}$ was used to collect Raman spectra. Spectra were acquired in scan mode from 400 to $4000 \mathrm{~cm}^{-1}$ using an integration time typically between 10 to $50 \mathrm{sec}$. The microscope objective employed was typically $\times 20$ with occasional spectra taken at $\times 10$ or $\times 50$ having spot diameters of 14,28 and $5 \mu \mathrm{m}$, respectively. The spectra presented here are single scans and are corrected for background. Spectra were taken from at least three areas of each sample to ensure that the spectra are representative of the material.

\section{HRTEM Lattice Fringe Image Analysis}

Using a fringe analysis program, the distribution of fringe lengths can be obtained. The algorithm exists as a macro, running under Optimas version 6.5 [43]. Clearly any image analysis program needs input parameters to deal with the limitations in distinguishing fine features, adjacent objects, gray-scale levels and overall image contrast as determined by focusing variability. Therefore, this program features a menu driven interface for selection of the region of interest, correction for uneven illumination across the image (common in HRTEM imaging), spatial filtering prior to processing and a binary thresholding operation which extracts fringe areas from the background. The program also allows retouching to blank out any artifacts that lie within the region of interest that do not correspond to image data.

After the aforementioned image refinements, the user must input fringe parameters for the maximum join distance and minimum fringe length. The former parameter is used to repair fringes that have been bisected due to image artifacts or as a result of filtering or thresholding processes. Two fringe segments whose orientation angle is similar and whose endpoints lie within the $\mathrm{N} \times \mathrm{N}$ pixel neighborhood specified by this parameter will be joined and thereafter considered as one fringe. The purpose of the minimum fringe length is to discard any fringes whose length is less than this parameter. Execution of the macro utilizes these parameters to convert an image from grayscale to binary. Carbon layer-plane thickness, which may increase with decreasing focus quality, is made constant at one pixel, creating a skeletonized, binary image. Nonphysical conditions, such as sharp bends are also detected and separated. Among other outputs, the program displays the length of each fringe. A histogram is readily created from such data. 


\section{Results and Discussion}

Figure 1 shows TEM images of the raw starting material, Cabot R250. With the outer graphene segments of the raw starting material being circumferential to the particle, they are properly aligned to anneal together. These outer shells or graphitic segments can then serve as templates for the less organized carbon within the particle interior, seen in figure 1(a). Figure 2 shows selected HRTEM images of the carbons subjected to different heat treatment temperatures of 1350, 1950, 2300 and $3000{ }^{\circ} \mathrm{C}$, each representative of over 50 images. The growth in graphitic structure becomes markedly apparent with increasing thermal treatment. As observed for highly thermally annealed carbon blacks, the particles evolve towards faceted polygons with hollow interiors [44]. As seen, several parallel stacks of graphitic layer planes comprise each wall of the polygon. The net effect of increasing heat treatment temperature is to induce an increase in the number of stacked graphitic segments, improve their relative alignment and in particular, extend their length. The focus here is on the latter quantity, as it pertains directly to the anisotropic reactivity of carbon.

Figure 3 shows the skeletonized images corresponding to each HRTEM image shown in figure 2. The image processing operations described above have been applied to the raw image data to obtain these processed images. As observed, these images display high similarity to the length and orientation of lattice fringes seen in the HRTEM input images. This visual comparison qualitatively verifies the processing fiduciary relative to the HRTEM data. These binary images show a clear increase in fringe length across the series of annealed carbon blacks. Individual fringe lengths were abstracted from these images and the subsequent distributions are summarized in the histograms presented in figure 4 . With increasing heat treatment temperature, the relative percentage of short fringes declines while that of longer fringes increases. This increase is attributed to both joining of adjacent fringes, where their mobility is aided by the elevated temperature, and addition of adjacent random and disordered carbon to lamella. We note that for these samples, tortuosity and relative orientation of parallel graphitic segments are not highly variable and consequently will not be pursued further here.

\section{Raman Comparison}

Image fringe analysis provides a nonintegrated, direct measure of the soot nanostructure. Relative to traditional measures of graphitic structure such as Raman spectroscopy, it offers three advantages: (1) image fringe analysis provides a detailed measure of the graphitic structure as described by the distribution of graphene segment lengths. Additional capabilities include tortuosity and curvature, to be discussed elsewhere; (2) based on HRTEM, it can provide spatially resolved measures of variations in lattice fringe structure within carbon structures; and (3) it can be applied to vanishingly small (nanogram) samples. Nevertheless, it is instructive to compare the fringe analysis results with those provided by Raman for comparison of the fringe length data, i.e., relative graphitic content.

Raman spectroscopy has been tested as a method for determining the planar crystallite dimensions of carbons that possess limited long-range order [45]. Several measures have been applied to the spectra that have been correlated with the extent of graphitic structure, such as line-width, peak positions and peak intensity ratios [46]. Two spectral peaks characterize the first order Raman spectra of carbon materials; a very strong, high-frequency, in-plane stretching mode $\left(E_{2 g}\right.$ or " $G$ " peak near $\left.1580 \mathrm{~cm}^{-1}\right)$ and a weaker, low-frequency mode $\left(A_{1 g}\right.$ or "D" peak near $\left.1360 \mathrm{~cm}^{-1}\right)$ [47]. The former corresponds to an in-plane stretching motion of the graphitic layer planes while the latter arises from a breakdown of the Raman selection rules attributed to the finite-sized regions of graphitic structure. Hence its nomenclature as the "disorder activated" transition. 
The intensity ratio of these peaks has been interpreted as a measure of the in-plane crystallite dimensions [45]. Strong monotonic correlations have been shown between the G/D intensity ratio and heat treatment temperature [48-49]. The most consistent semi-empirical relation to be developed is that by Knight and White, who found the in-plane crystallite dimension, $\mathrm{L}_{\mathrm{a}}$, to be an approximately linear function of the ratio of the integrated spectral peak intensities, $\left(\mathrm{I}_{\mathrm{g}} / \mathrm{I}_{\mathrm{d}}\right)$ as applied to a wide range of carbon materials including pyrolytic, glassy, amorphous and crystalline graphite [45]. This relationship is particularly appealing as it affords a direct comparison with the graphitic fringe length as provided by the fringe analysis program. The Raman spectra of the different heat-treated carbon black samples are plotted in figure 5. The change in relative intensities is consistent with increasing graphitization induced by higher temperatures. The narrowing of the $\mathrm{D}$ and $\mathrm{G}$ peaks indicates increasing homogeneity of the sample as disordered carbon is reorganized and/or joins to growing lamella.

Figure 6 shows graphs of the integrated intensity ratio of the G and D peaks of the carbon nanoonions as a function of the heat treatment temperature. Plotted for comparison are the medians of the fringe length histograms shown in figure 4 corresponding to the selected heat treatment temperatures. Particularly encouraging is the monotonic relation exhibited by both the Raman integrated intensity ratio and lattice fringe length with increasing temperature. In fact, each best fit line possess a rather similar slope, as seen in figure 6 . The monotonic behavior confirms the dependence of each measure upon graphitic structure. The linear behavior common to each quantity validates their self consistency of each as a gauge of the soot nanostructure.

As noted, peak intensities from Raman spectroscopy, when applied to disordered carbon materials possessing very small domains of graphitic structure, are affected by layer plane curvature, degree of turbostratic stacking, etc. [50]. Additionally, we note that the lattice fringe lengths observed using HRTEM are averaged over the viewing angle and hence any anisotropy in the dimensions of the lamella will be subject to an angle-dependent length reduction within the image. (However, this factor would be consistent between HRTEM images of different carbon nanostructures, thus relative values would be accurate.) Therein we refrain from using a multiplicative semi-empirical factor to convert the Raman intensity ratios into fringe length or vice versa. Rather, each method provides a different relative measure of fringe length. Nevertheless, the approximate agreement and clear monotonic correlation supports the fringe analysis program as providing an accurate measure of the graphitic structure, and hence potential oxidation characteristics of the carbon.

\section{Conclusion}

A lattice fringe analysis program has been developed to quantify the data conveyed by HRTEM images. By providing a direct measure of the molecular level of graphitic structure, it is expected that its application could provide predictive capabilities for carbon reactivity, particularly towards oxidation. The robustness of this program is demonstrated by using a series of carbon blacks possessing different levels of graphitic structure, prepared at different heat treatment temperatures. Its credibility is benchmarked against a traditional measure of graphitic structure, as provided by Raman analysis. Lattice fringe length is found to be monotonic with the level of graphitic structure as provided by the ratio of the integrated intensities of the G/D spectral peaks in the Raman spectra. Reciprocally, for production purposes, the G/D band intensity ratio can serve as a direct measure of the lattice fringe reactivity. 


\section{References}

1. Gaydon, A.G. and Wolfhard, H.G., Flames, Their Structure, Radiation and Temperature, 3rd. Ed. Chapman and Hall, London, 1970.

2. Physical and Chemical Aspects of Combustion, A tribute to Irvin Glassman, (F.L. Dryer and R.F. Sawyer, Eds.) Gordon and Breach Science Publishers, 1997, pp. 107-266.

3. Proceedings of the International Workshop on Mechanisms and Models of Soot Formation (H. Bockhorn Ed.) Springer-Verlag, Heidelberg, Germany, 1994.

4. Frenklach, M. and Wang, H., Twenty-Third Symposium (International) on Combustion, The Combustion Institute, Pittsburgh, PA, 1990, p. 1559.

5. Miller, J.H., Twenty-Third Symposium (International) on Combustion, The Combustion Institute, Pittsburgh, PA, 1990, pp. 91-102.

6. Howard, J.B., Twenty-Third Symposium (International) on Combustion, The Combustion Institute, Pittsburgh, PA, 1990, pp. 1107-1121.

7. Hepp, H., Siegmann, K., and Sattler, K., Chem. Phys. Lett. 1995, 233, 16.

8. Xu, F., Lin, K.-C., and Faeth, G.M., Comb. and Flame 1998, 115, 195.

9. Kronholm, D.F. and Howard, J.B., The Twenty-Eighth Symposium (International) on Combustion, The Combustion Institute, Pittsburgh, PA, 2000, pp. 2555-2561.

10. R.A. Dobbins, R.A. Fletcher, and W. Lu, "Laser microprobe analysis of soot precursor particles and carbonaceous soot," Combust. and Flame 1995, 100, 301.

11. Law, C.K. and Faeth, G.M., Prog. Energy Combust. Sci. 1994, $20,64$.

12. Santoro, R.J., Yeh, T.T., Horvath, J.J., and Semerjian, H.G., Combust. Sci. and Tech. 1987, 53, 89.

13. Glassman, I., The Twenty-Second Symposium (International) on Combustion, The Combustion Institute, Pittsburgh, PA, 1988, pp. 295-311.

14. Oberlin, A., Carbon 1984, 22, 521.

15. Lewis, I.C., Carbon 1982, 20, 519.

16. Wornat, M.J., Hurt, R.H., Yang, N.Y.C., and Headley, T.J., Combust. and Flame 1995, 100, 131.

17. Wilks, K.R., Mastalerz, M., Bustin, R.M., and Ross, J.V., Int. J. of Coal Geology 1993, 22, 247.

18. Buseck, P.R., Go-Jun, H., and Keller, L.P., Energy and Fuels 1987, 1, 105.

19. Suuberg, E.M., Wojtowicz, M., and Calo, J.M., Carbon 1989, 27, 431.

20. Carbon Black Science and Technology, 2nd ed. J.B. Donnet, R.C. Bansal, and M.-J. Wang eds. Marcel Dekker, Inc. 1993.

21. Smith, W.R. and Polley, M.H., J. Chem. Phys. 1956, p. 689.

22. Thomas, J.M., Microscopy studies of graphite oxidation, in The Chemistry and Physics of Carbon, (P.L. Walker, Jr., Ed.) 1965, Vol. 1, Ch. 2.

23. Henning, G.R., Chemistry and Physics of Carbon, (P.L. Walker, Jr., Ed.), 1966, Vol. 2, Ch. 1

24. Levy, M. and Wong, P., J. of The Electrochem. Soc. 1964, 11, 1088.

25. Rosner, D.E. and Allendorf, H.D., AIAA Journal 1968, 6, 650.

26. Donnet, J.B., Carbon 1982, 20, 267.

27. Marsh, H., Introduction to Carbon Science, Butterworths, London, 1989, Ch. 4, pp. 107.

28. Smith, O.I., Prog. Energy Combust. Sci. 1981, 7, 275.

29. Hurt, R.H., Dudek, D.R., Longwell, J.P., and Sarofim, A.F., Carbon 1988, 26, 433.

30. Hurt, R.H., Sarofim, A.F. and Longwell, J.P., Combust. and Flame 1993, 95, 430.

31. Fletcher, T.H., Ma, J., Rigby, J.R., Brown, A.L., and Webb, B.W., Prog. Energy Combust. Sci. 1997, 23, 283.

32. Hurt, R.A., The Twenty Eighth Symposium (International) on Combustion, The Combustion Institute, Pittsburgh, PA, 1998, pp. 2887-2904.

33. Davis, K.A., Hurt, R.H., Yang, N.Y., and Headley, T.J., Combust. and Flame 1995, 100, 31. 
34. Heckman, F.A. and Harling, D.F., Rubber Chem. and Technol. 1966, 39, 1. See also The Presentation at the Annual meeting of the Division of Rubber Chemistry, The American Chem. Soc., Miami Beach.

35. Hess, W.M., Ban, L.L., Eckert, F.J., and Chirico, V. Rubber Chem. and Technol. 1968, 41, 356.

36. Marsh, P.A., Voet, A., Mullens, T.J., and Price, L.D., Rubber Chem. and Technol. 1970, 43, 470.

37. Vander Wal, R.L. and Choi, M.Y., Carbon 1999, 37, 231.

38. Vander Wal, R.L., Combust. Sci. and Technol. 1997, 126, 333.

39. Shim, H.-S., Hurt, R.H., and Yang, N.Y.C., Carbon 2000, 38, 29.

40. Dukhan, X.Z., Kantorovich, I.I., Bar-Ziv, E., Kandas, A., and Sarofim, A.F., Twenty-Sixth Symposium (International) on Combustion, The Combustion Institute, Pittsburgh, PA 1996, pp. 3111-3118.

41. Akamatu, H. and Kuroda, H., Proc. 4th Carbon Conference, Pergamon Press, Inc., New York, 1960, pp. 355.

42. Emmerich, F.G., Carbon 1995, 33, 1709.

43. Optimas, Media Cybernetics L.P., Siver Springs, MD.

44. Millward, G.R. and Jefferson, D.A., Lattice resolution of carbons by electron microscopy, in "The Chemistry and Physics of Carbon," Vol. 14, (P.L. Walker and P.A. Thrower, Eds.), Marcel Dekker Inc., New York, 1970, Ch. 1.

45. Knight, D.S. and White, W.B., J. Mater. Sci. 1989, 4, 385.

46. Fischbach, D.B. and Couzi, M., Carbon 1986, 24, 365 (and references therein).

47. Tuinstra, E. and Koenig, J., J. Chem. Phys. 1970, 53, 1126.

48. Nakamizo, M., Kammereck, R., and Walker, Jr., P.L., Carbon 1974, 12, 259.

49. Emmerich, F.G., Carbon 1995, 33, 1709.

50. Dresselhaus, M.S., Dresselhaus, G., Sugihara, K., Spain, I.L., and Goldberg, H.A., Graphite Fibers and Filaments, Springer-Verlag, Heidelberg Germany 1988, Ch. 4, pp. 97. 

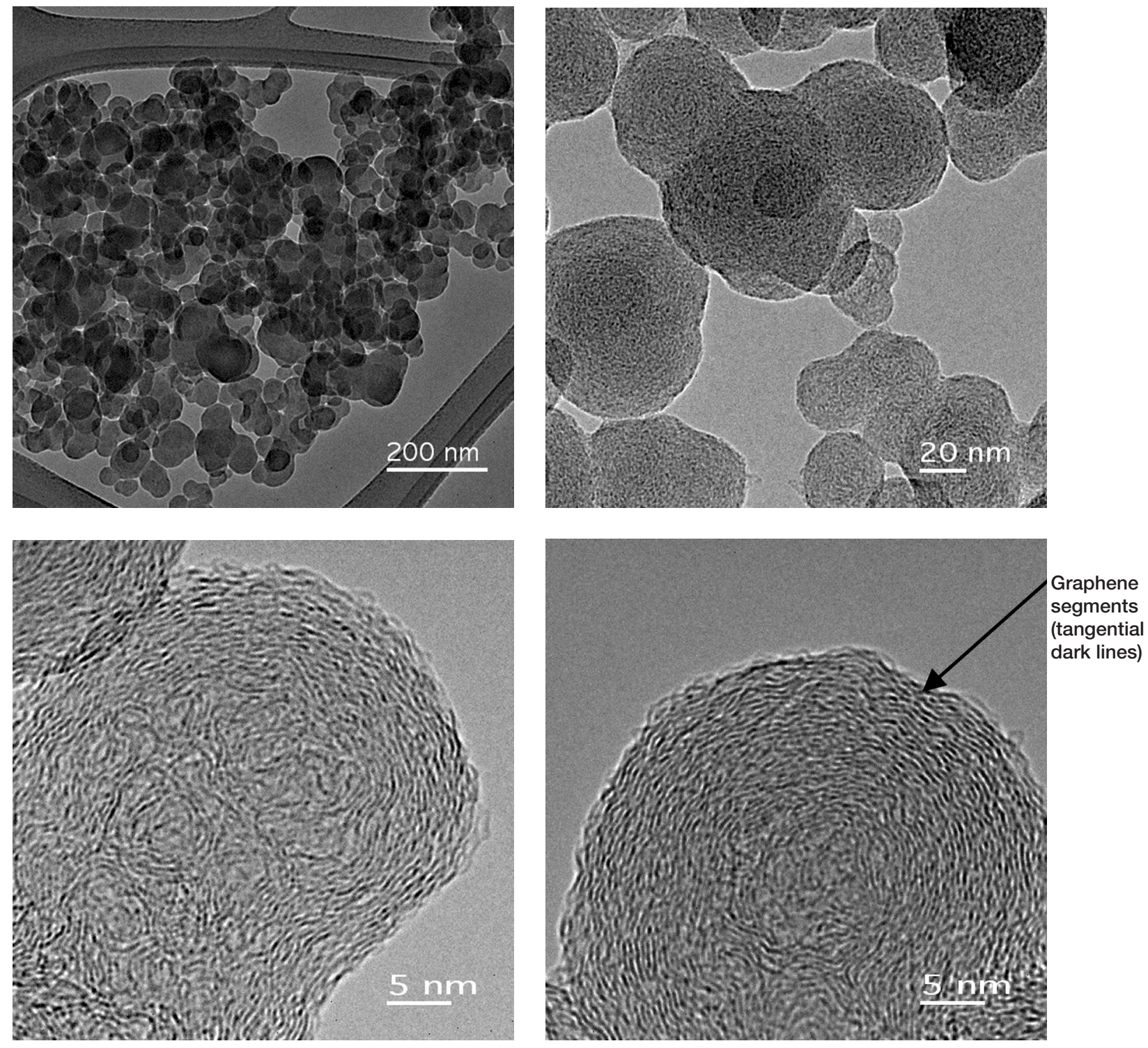

Figure 1.-TEM images of the raw material (carbon black) used for producing the graphitized carbon by heat treatment. The material product designation is Cabot R250. 

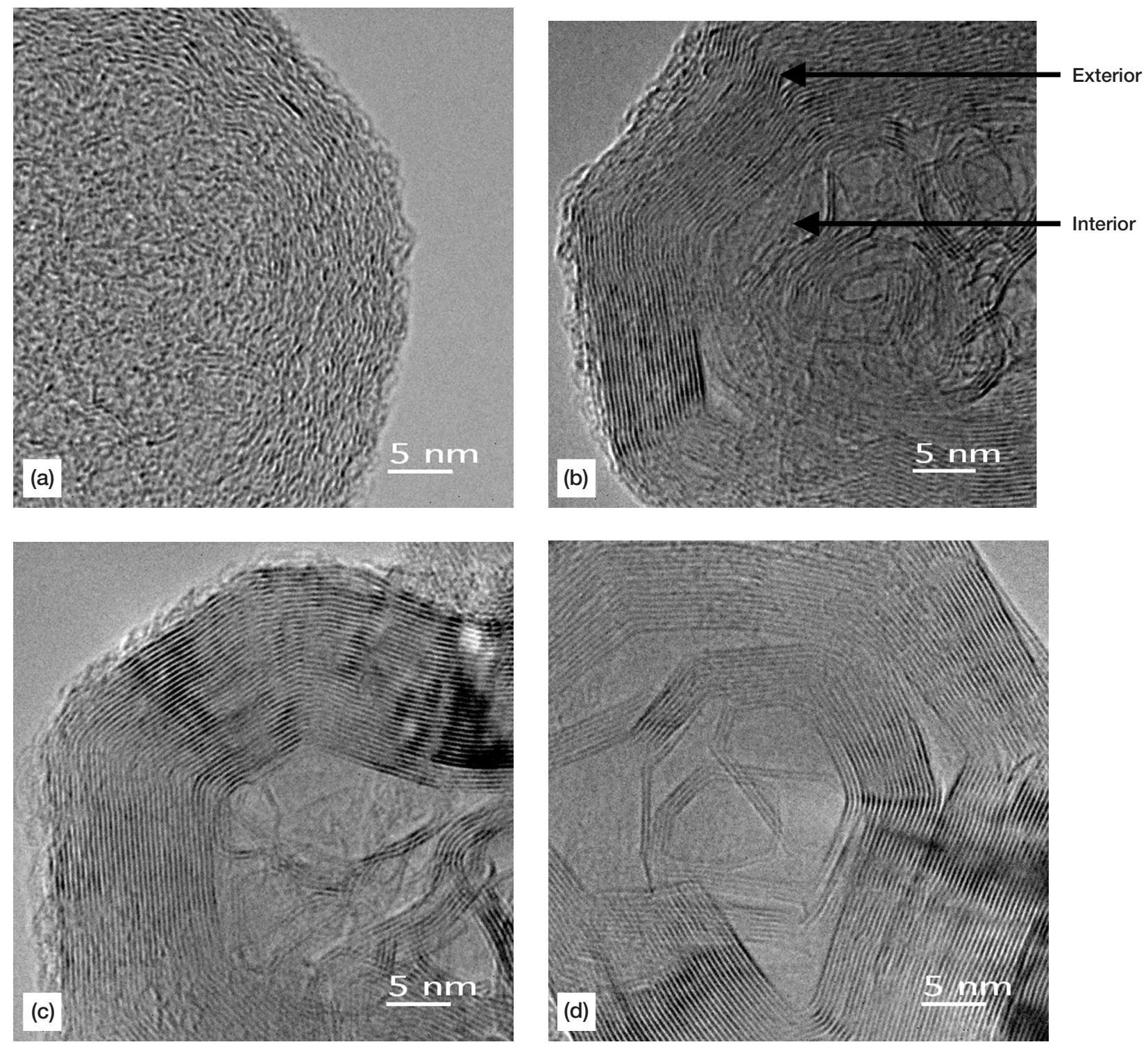

Figure 2.-High resolution transmission electron microscopy images of the carbon black prepared by heat treatment at temperatures. (a) $1350^{\circ} \mathrm{C}$. (b) $1950^{\circ} \mathrm{C}$. (c) $2300^{\circ} \mathrm{C}$. (d) $3000^{\circ} \mathrm{C}$. 

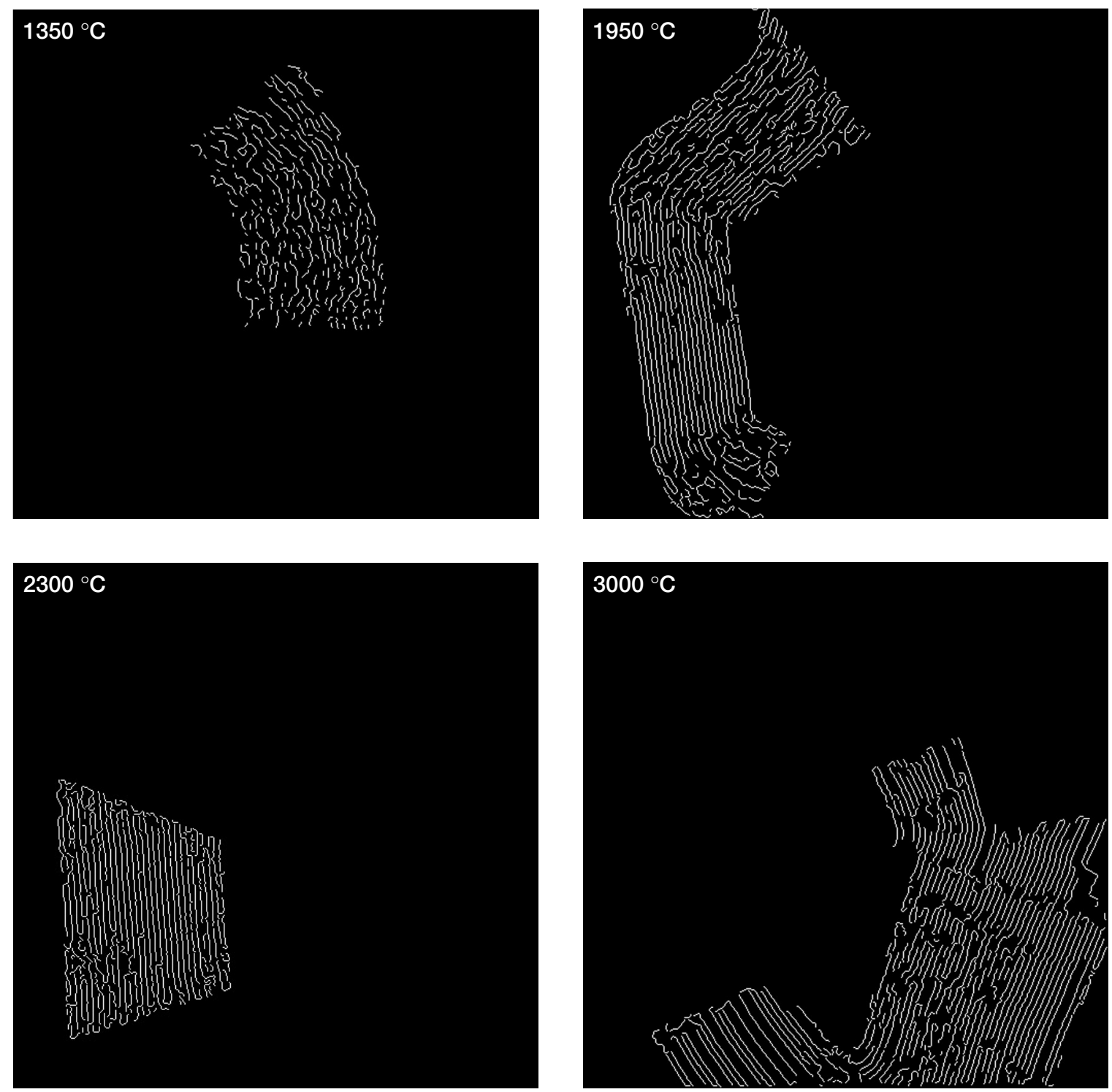

Figure 3.-Skeletonized images obtained by applying the lattice fringe analysis program to the HRTEM images showm in figure 2 of the carbon black soot processed at the different elevated temperatures. 

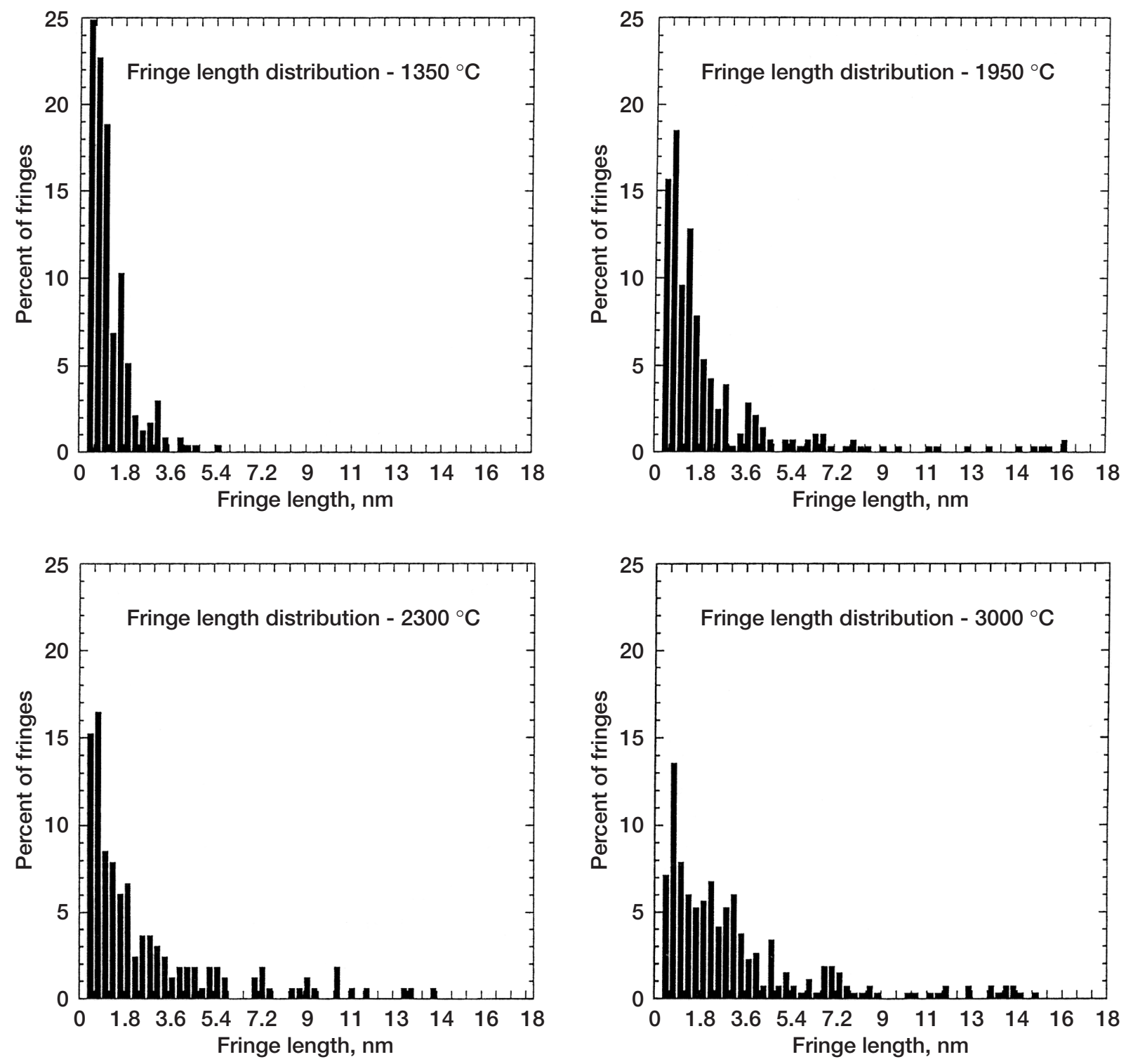

Figure 4.-Histograms of the lattice fringe lengths observed spatially in the binary processd images shown in figure 3. See text for detail. 


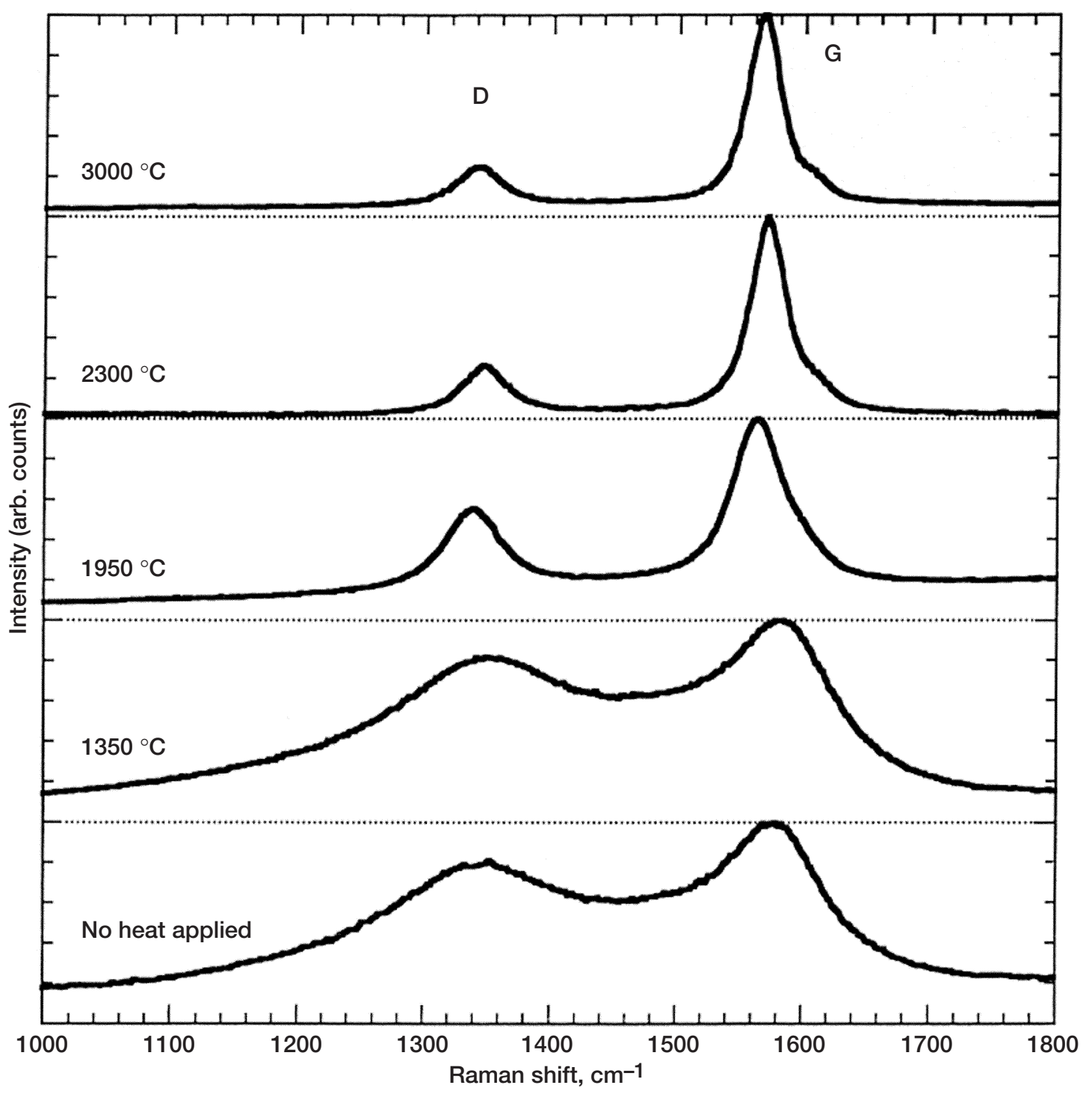

Figure 5.-Raman intensity plots (first-order spectra) for the carbon black subjected to the different heat treatment temperatures. 


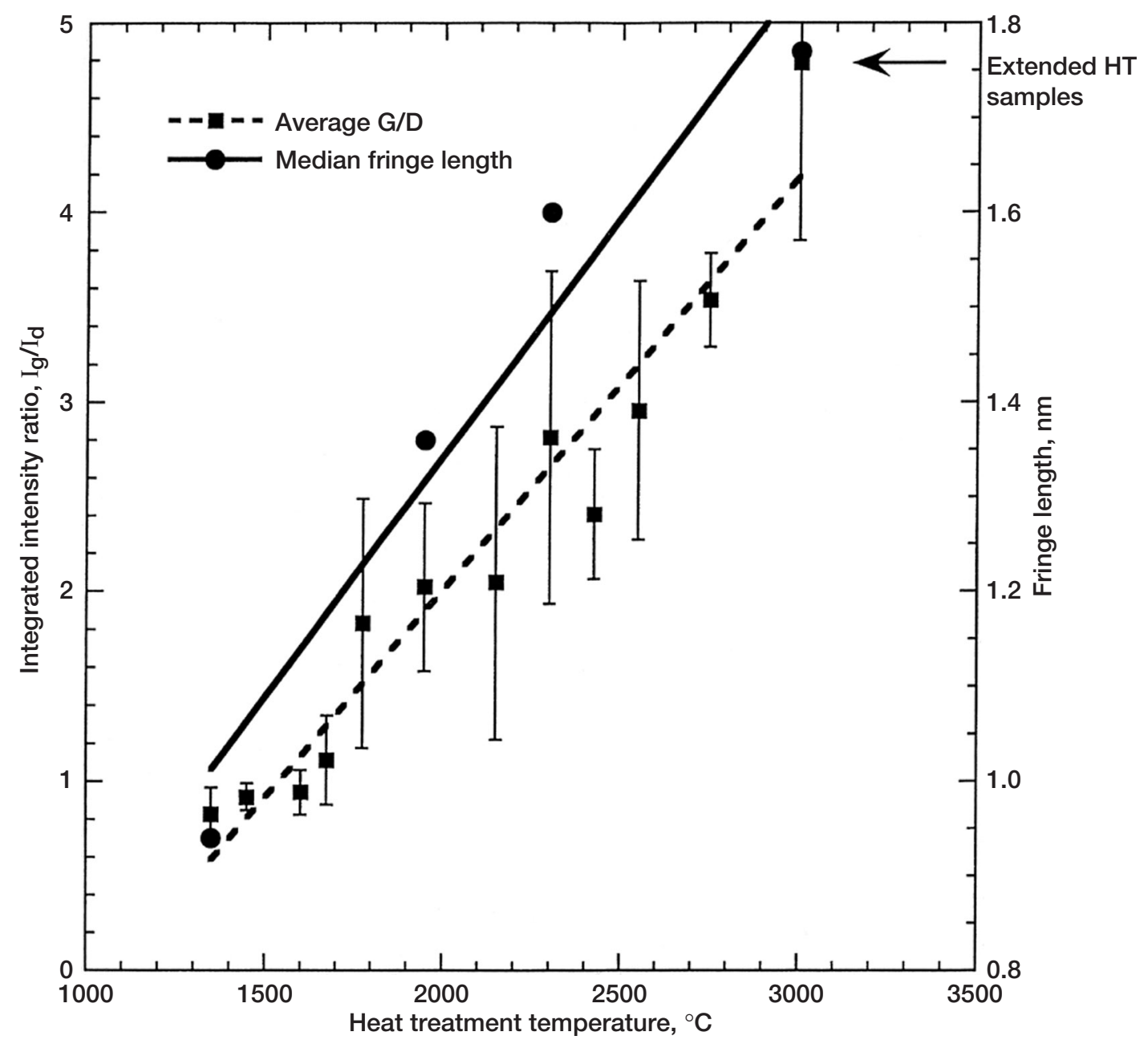

Figure 6.-Plots of the mean lattice fringe lengths obtained from histograms in figure 4 and the ratios of the integrated intensities of the Raman $G$ and $D$ spectral peaks $\left(I_{g} / I_{d}\right)$ obtained from figure 5 . 
Public reporting burden for this collection of information is estimated to average 1 hour per response, including the time for reviewing instructions, searching existing data sources, gathering and maintaining the data needed, and completing and reviewing the collection of information. Send comments regarding this burden estimate or any other aspect of this collection of information, including suggestions for reducing this burden, to Washington Headquarters Services, Directorate for Information Operations and Reports, 1215 Jefferson Davis Highway, Suite 1204, Arlington, VA 22202-4302, and to the Office of Management and Budget, Paperwork Reduction Project (0704-0188), Washington, DC 20503.

\begin{tabular}{|l|l|l}
\hline 1. AGENCY USE ONLY (Leave blank) & $\begin{array}{c}\text { 2. REPORT DATE } \\
\text { May } 2003\end{array}$ & $\begin{array}{r}\text { 3. REPORT TYPE AND DATES COVERED } \\
\text { Technical Memorandum }\end{array}$
\end{tabular}

\section{TITLE AND SUBTITLE}

Carbon Nanostructure Examined by Lattice Fringe Analysis of High Resolution

Transmission Electron Microscopy Images

\section{6. $\operatorname{AUTHOR(S)}$}

Randy L. Vander Wal, Aaron J. Tomasek, Kenneth Street, William K. Thompson, and David R. Hull

\section{PERFORMING ORGANIZATION NAME(S) AND ADDRESS(ES)}

National Aeronautics and Space Administration

John H. Glenn Research Center at Lewis Field

Cleveland, Ohio 44135-3191

\section{SPONSORING/MONITORING AGENCY NAME(S) AND ADDRESS(ES)}

National Aeronautics and Space Administration

Washington, DC 20546-0001

\section{FUNDING NUMBERS}

WBS-22-101-12-06

8. PERFORMING ORGANIZATION REPORT NUMBER

E-13835

\section{SUPPLEMENTARY NOTES}

Randy L. Vander Wal and Aaron J. Tomasek, National Center for Microgravity Research, Cleveland, Ohio; Kenneth Street, William K. Thompson, and David R. Hull, NASA Glenn Research Center. Responsible person, Randy L. Vander Wal, organization code 6711, 216-433-9065.

12a. DISTRIBUTION/AVAILABILITY STATEMENT 12b. DISTRIBUTION CODE

Unclassified - Unlimited

Subject Category: 25

Distribution: Nonstandard

Available electronically at http://gltrs.grc.nasa.gov

This publication is available from the NASA Center for AeroSpace Information, 301-621-0390.

\section{ABSTRACT (Maximum 200 words)}

The dimensions of graphitic layer planes directly affect the reactivity of soot towards oxidation and growth. Quantification of graphitic structure could be used to develop and test correlations between the soot nanostructure and its reactivity. Based upon transmission electron microscopy images, this paper provides a demonstration of the robustness of a fringe image analysis code for determining the level of graphitic structure within nanoscale carbon, i.e., soot. Results, in the form of histograms of graphitic layer plane lengths, are compared to their determination through Raman analysis.

\section{SUBJECT TERMS}

Nanoparticles; Nanostructure; Transmission electron microscopy; Raman spectroscopy

17. SECURITY CLASSIFICATION OF REPORT

Unclassified

18. SECURITY CLASSIFICATION
OF THIS PAGE
Unclassified

19. SECURITY CLASSIFICATION OF ABSTRACT

Unclassified
15. NUMBER OF PAGES

19

16. PRICE CODE

\section{LIMITATION OF ABSTRACT}

